\title{
Tribological Behavior of Hydraulic Oils Under Different Motion Modes
}

\author{
An Haizhen ${ }^{1 *}$, Chen $\mathrm{Li}^{1}$, Zhen Penghou ${ }^{1}$ and Liu Min ${ }^{1}$ \\ ${ }^{1}$ Jiangsu Xuzhou Construction Machinery Research Institute Xuzhou Construction Machinery Group, Xuzhou, Jiangsu, China
}

\begin{abstract}
In order to study the tribological properties of different hydraulic oils under different motion modes, four-ball tester and block-on-ring tester were used to optimize the test parameters and evaluate performance of commercial hydraulic oils. The results showed that the optimized test methods under the form of point and line motion modes can better evaluate the extreme pressure and anti-wear performance of hydraulic oi. There was a negatively correlation between extreme pressure and anti-wear performance; this method can provide a basis for the reasonable selection of lubricating oil in hydraulic system.
\end{abstract}

\section{Introduction}

As an important part of the hydraulic system, hydraulic oil is not only the medium of energy transfer, conversion and control of auxiliary valves, but also plays the role of cooling, cleaning, lubrication and sealing. The hydraulic system of construction machinery has been developing towards high pressure, high speed, high power, high performance, high precision, large flow and system control to a more complex and flexible direction [1-3]. In order to effectively ensure the normal operation of hydraulic components under the harsh conditions of high pressure, high speed, heavy load and impact, higher requirements are put forward for the extreme pressure and anti-wear performance of the matching hydraulic oil. The excellent extreme pressure and anti-wear performance of hydraulic oil can reduce the wear of hydraulic components, prolong the service life, reduce the leakage and burst probability, and improve work efficiency [4].

Therefore, in order to effectively evaluate the extreme pressure and anti-wear performance of hydraulic oil from multiple angles, this paper investigates the tribological properties of point and line motion modes. By using four-ball tester and block-on-ring tester (Timken tester), through reasonable optimization of test parameters and evaluation indexes, the extreme pressure and anti-wear performance of hydraulic oils of different quality grades can be effectively distinguished and controlled.

\section{Experimental details}

\subsection{Materials}

Standard steel balls were used for four-ball tester, and standard test ring and test block were used for ring block test; twenty six kinds of market acquired hydraulic oil.

\subsection{Tribological Tester and test method}

Four-ball tester was used to evaluate the anti-wear performance of hydraulic oil, and block-on-ring tester was used to evaluate extreme pressure performance of hydraulic oil [5-6]. Firstly, the point contact four ball test was carried out. In order to select the test parameters effectively, high pressure hydraulic oil A and hydraulic transmission oil B with large performance differences were selected for testing. Taking 4 factors and 3 levels, the experimental scheme was designed according to $\mathrm{L}_{9}\left(3^{4}\right)$ orthogonal design. The larger the difference of wear scar diameter is, the better the distinguishing performance of the two test oils is, on the contrary, the worse the distinguishing performance of the two test oils is. At the same time, the appearance of abnormal noise, the morphology of wear spots and the change of oil temperature are analyzed. The experimental design is shown in table 1.

As is shown in table 1 that condition 4 (90 $\mathrm{min}, 600$ $\mathrm{r} / \mathrm{min}, 75^{\circ} \mathrm{C}$ and $588 \mathrm{~N}$ ) shows a stronger distinction in oil evaluation than the other eight test sequences. It can be seen from the range analysis that when the test condition is $90 \mathrm{~min}, 1200 \mathrm{r} / \mathrm{min}, 96{ }^{\circ} \mathrm{C}$ and $588 \mathrm{~N}$, it also has good discrimination between the two oils. For further cross validation, the design test scheme is shown in table 2 .

\footnotetext{
* Corresponding author: 18205213535@163.com
} 
Table 1. Orthogonal test design table.

\begin{tabular}{|c|c|c|c|c|c|c|c|c|}
\hline \multirow{2}{*}{\multicolumn{2}{|c|}{ Number }} & \multirow{2}{*}{$\begin{array}{l}\text { Time } \\
/ \text { min }\end{array}$} & \multirow{2}{*}{$\begin{array}{l}\text { Speed/ } \\
\text { (r/min) }\end{array}$} & \multirow{2}{*}{$\begin{array}{l}\text { Tempe } \\
\text { rature } \\
{ }^{\circ} \mathrm{C}\end{array}$} & \multirow{2}{*}{$\begin{array}{c}\text { Load } \\
/ \mathbf{N}\end{array}$} & \multicolumn{2}{|c|}{ Wear scar diameter /mm } & \multirow{2}{*}{$\begin{array}{l}\text { Wear scar diameter } \\
\text { difference } / \mathrm{mm}\end{array}$} \\
\hline & & & & & & A & $\mathrm{B}$ & \\
\hline \multicolumn{2}{|c|}{1} & 60 & 600 & 54 & 196 & 0.32 & 0.35 & 0.03 \\
\hline \multicolumn{2}{|c|}{2} & 60 & 1200 & 75 & 392 & 0.42 & 0.53 & 0.11 \\
\hline \multicolumn{2}{|c|}{3} & 60 & 1800 & 96 & 588 & $0.95 *$ & $1.07 *$ & 0.12 \\
\hline \multicolumn{2}{|c|}{4} & 90 & 600 & 75 & 588 & 0.49 & 0.63 & 0.14 \\
\hline \multicolumn{2}{|c|}{5} & 90 & 1200 & 96 & 196 & 0.33 & 0.40 & 0.07 \\
\hline \multicolumn{2}{|c|}{6} & 90 & 1800 & 54 & 392 & $0.60^{*}$ & $0.68 *$ & 0.08 \\
\hline \multicolumn{2}{|c|}{7} & 120 & 600 & 96 & 392 & 0.42 & 0.53 & 0.11 \\
\hline \multicolumn{2}{|c|}{8} & 120 & 1200 & 54 & 588 & $0.65 *$ & $0.79 *$ & 0.14 \\
\hline \multicolumn{2}{|c|}{9} & 120 & 1800 & 75 & 196 & 0.37 & 0.40 & 0.03 \\
\hline \multirow{7}{*}{$\begin{array}{l}\text { range } \\
\text { analysi } \\
\mathrm{s}\end{array}$} & $\mathrm{K}_{1}$ & 0.26 & 0.28 & 0.25 & 0.13 & & & \\
\hline & $\mathrm{K}_{2}$ & 0.29 & 0.32 & 0.28 & 0.30 & & & \\
\hline & $\mathrm{K}_{3}$ & 0.28 & 0.23 & 0.30 & 0.40 & & & \\
\hline & $\mathrm{k}_{1}$ & 0.09 & 0.09 & 0.08 & 0.04 & & & \\
\hline & $\mathrm{k}_{2}$ & 0.10 & 0.11 & 0.09 & 0.10 & & & \\
\hline & $\mathrm{k}_{3}$ & 0.09 & 0.08 & 0.10 & 0.13 & & & \\
\hline & $\mathrm{R}_{\mathrm{j}}$ & 0.01 & 0.03 & 0.02 & 0.09 & & & \\
\hline \multicolumn{3}{|c|}{ note } & \multicolumn{3}{|c|}{ * Oil film rupture } & & & \\
\hline
\end{tabular}

Table 2. Orthogonal test design table.

\begin{tabular}{|c|c|c|c|c|c|c|c|}
\hline \multirow{2}{*}{ Number } & \multirow{2}{*}{$\underset{/ N}{\text { Load }}$} & \multirow{2}{*}{$\begin{array}{l}\text { Time } \\
/ \text { min }\end{array}$} & \multirow{2}{*}{$\begin{array}{c}\text { Temperatur } \\
\mathbf{e} \\
{ }^{\circ} \mathrm{C} \\
\end{array}$} & \multirow{2}{*}{$\begin{array}{l}\text { Speed } \\
/(\mathbf{r} / \mathrm{min})\end{array}$} & \multicolumn{2}{|c|}{ Wear scar diameter /mm } & \multirow{2}{*}{$\begin{array}{l}\text { Wear scar diameter } \\
\text { difference } / \mathrm{mm}\end{array}$} \\
\hline & & & & & $\mathbf{A}$ & B & \\
\hline I & 588 & 90 & 75 & 600 & 0.47 & 0.62 & 0.15 \\
\hline II & 588 & 90 & 75 & 1200 & $0.65^{*}$ & $0.82 *$ & 0.17 \\
\hline III & 588 & 90 & 96 & 600 & 0.46 & 0.60 & 0.14 \\
\hline IV & 588 & 90 & 96 & 1200 & $0.71 *$ & $0.82 *$ & 0.11 \\
\hline Note & \multicolumn{7}{|c|}{ * Oil film rupture } \\
\hline
\end{tabular}

Table 2 shows that both condition I and III can distinguish tribological performance of hydraulic oils effectively. The oil film of the tow oils under condition IIand IV were broken, the oils could not form effective lubrication. Considering the common temperature of hydraulic oil in the hydraulic system and the maximum allowable working temperature, group I ( $588 \mathrm{~N}, 90 \mathrm{~min}$, $75^{\circ} \mathrm{C}, 600 \mathrm{r} / \mathrm{min}$ ) was selected as the final evaluation test condition.

The design of the extreme pressure by ring block tester is based on the condition of the four ball test. Temperature was $75^{\circ} \mathrm{C}$, during time was $90 \mathrm{~min}$, and rotating speed was $600 \mathrm{r} / \mathrm{min}$. The initial positive pressure between each pair of friction pairs was $240 \mathrm{~N}$, and load increase gradient was $24 \mathrm{~N}$, when scoring or seizure occurs, test load dropped by $12 \mathrm{~N}$, until found the load before the oil film breaks. Further, under the maximum load, a 90 minute friction test was carried out.

Based on the above analysis, the final hydraulic oil tribological performance test scheme parameters are shown in table 3 , and test conditions are close to actual working conditions.
Table 3. Hydraulic oil tribological performance test conditions.

\begin{tabular}{|l|l|c|c|c|}
\hline Tester & Load/N & $\begin{array}{l}\text { Speed } \\
/(\mathbf{r} / \text { min) }\end{array}$ & $\begin{array}{c}\text { Tempera } \\
\text { ture } /{ }^{\circ} \mathrm{C}\end{array}$ & $\begin{array}{c}\text { Time/ } \\
\text { min }\end{array}$ \\
\cline { 1 - 2 } $\begin{array}{l}\text { Four-ball } \\
\text { tester }\end{array}$ & 588 & \multirow{2}{*}{600} & 75 & 90 \\
\cline { 1 - 2 } $\begin{array}{l}\text { Timken } \\
\text { extreme } \\
\text { pressure tester }\end{array}$ & $\begin{array}{l}\text { load before } \\
\text { oil film } \\
\text { rupture }\end{array}$ & & & \\
\hline
\end{tabular}

\section{Results and discussion}

\subsection{Verification of hydraulic oil anti-wear performance test method}

According to the selected test conditions of anti-wear performance of hydraulic oil, five kinds of hydraulic oils were tested to verify the feasibility and distinguishability of the test conditions.

The wear scar diameters $(\mathrm{mm})$ corresponding to the 5 oils were $0.48,0.62,0.63,0.91$ and 0.96 respectively, as is shown in figure 1. The morphologies of wear scar are shown in figure 2, for wear scars of L-4 and L-5, abnormal changes occured, such as the scratch extends beyond the wear mark, and there was excessive metal 
accumulation outside the wear scar, during the test, the friction coefficient increased suddenly, the oil temperature increased, and the friction noise appeared. However, the other oils lubricated well, the surface of wear scars were smooth.

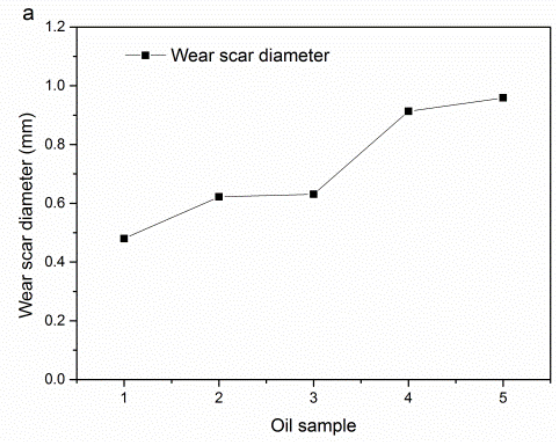

Fig.1. Validation of test method for hydraulic oils on anti-wear (a) performance.

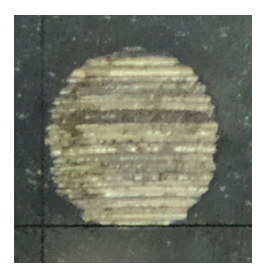

L-1

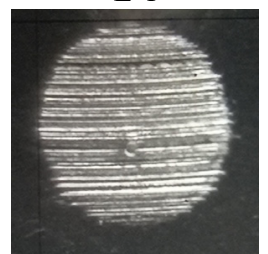

L-3

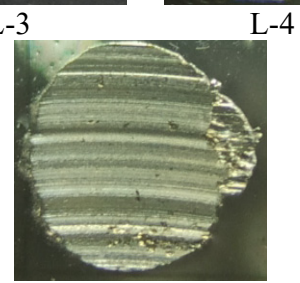

L-5

Figure 2. Morphologies of the wear scars.

It can be inffered from the above analyisis that oil film ruptured of L-4 and L-5, which inffered that antiwear performance of these two oils was poor under point contact mode. The above five kinds of oils could be roughly divided into three levels according to the wear scar diameters and morphologies, wear scar diameter is less than or equal to $0.5 \mathrm{~mm}, 0.5 \mathrm{~mm}$ to the upper limit of the lubrication load and oil film rupture.

The results show that the evaluation method can distinguish anti-wear performance of different quality grades of hydraulic oils under point contact mode. Therefore this method is one of the quality control indicators of anti-wear performance of hydraulic oils. Also this method can be used in the development of laboratory hydraulic oil, be used as a method of oil screening before bench test, and provide a basis for the rational selection of hydraulic oils.

\subsection{Verification of the extreme pressure performance test method of hydraulic oil block- on-ring test}

The test selected the above five types of hydraulic oil for futher research, and each oil was tested until the oil film rupture and seizure occurred of the ring block under line contact mode. After the selection of ultimate load, friction test under high load conditions were carried out. The test temperature was $75^{\circ} \mathrm{C}$, the speed was $600 \mathrm{r} / \mathrm{min}$, and the during time was $90 \mathrm{~min}$. The test results are shown in figure 3.

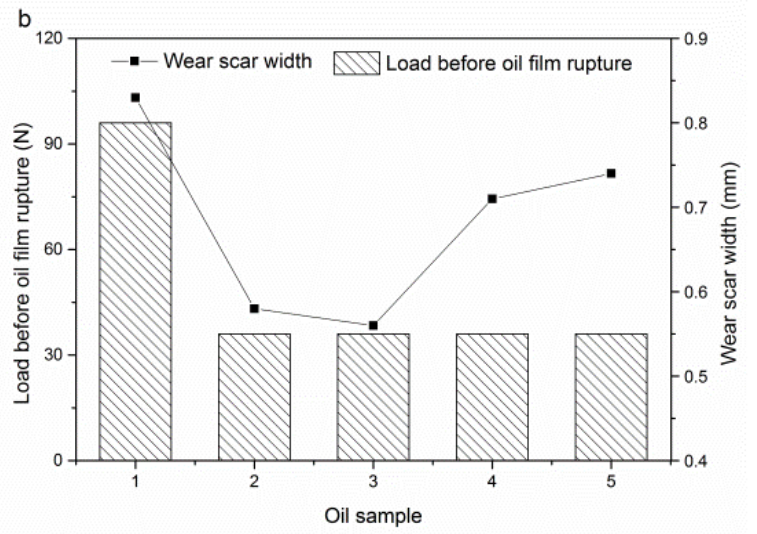

Fig. 3. Validation of test method for hydraulic oils on extreme pressure performance.

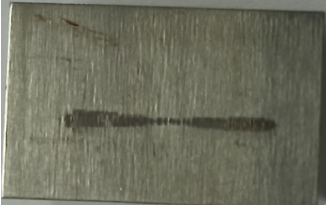

L-1

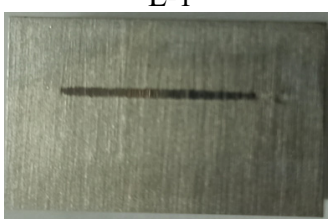

L-3

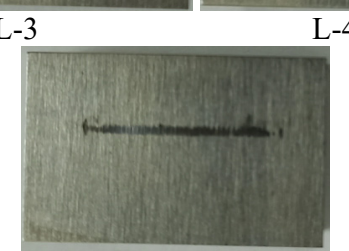

L-5

Fig. 4. Wear scar morphologies of hydraulic oils under high load.

The maximum load before oil film ruptures and the corresponding wear scar width are shown in figure 3, and the morphologies of the wear scars are shown in figure 4. Generally, when the surface of the oil film rupture, test block produces wide and deep plow mark damage along the sliding direction, and there is metal accumulation on the surface of the test ring.

As is shown in Figure 4, the film of these five oils had not broken during the endurance test. The oil film strength of L-1 was the highest, the load before oil filmed was $96 \mathrm{~N}$. L-1 showed better extreme pressure 
performance than the other 4 oils. As is shown in figure 3 and figure 4, although the oil film rupture load of the other 4 kinds of oil was the same, after a long during time test, wear scar width of L-4 and L-5 was higher than that of L-2 and L-3. On the one hand, it shows that L-4 and L-5 are more closer to oil film rupture than that of L-2 and L-3. On the other hand, the wear resistance of L-2 and L-3 is higher than that of L-4 and L-5 under the same load.

According to the above analysis it is reasonable to find the load-bearing limit first, and to carry out a during wear test under the load before the oil film breaks. The ring block test under this test condition can better distinguish different quality grades of hydraulic oils .

\subsection{Relationship analysis of hydraulic oil extreme pressure and anti-wear performance}

In order to initially study the correlation between antiwear performance and extreme pressure performance under different motion modes, four-ball tester and blockon-ring tester are used to carry out of 26 kinds of market acquired hydraulic oils, covering 9 lubricating oil brands.

Under point contact mode, the test load was $588 \mathrm{~N}$, temperature was $75^{\circ} \mathrm{C}$, the speed was $600 \mathrm{r} / \mathrm{min}$, and the during time was $90 \mathrm{~min}$. Under line contact mode, load before the oil film ruptures was founded first, and a long during time test was carried out.

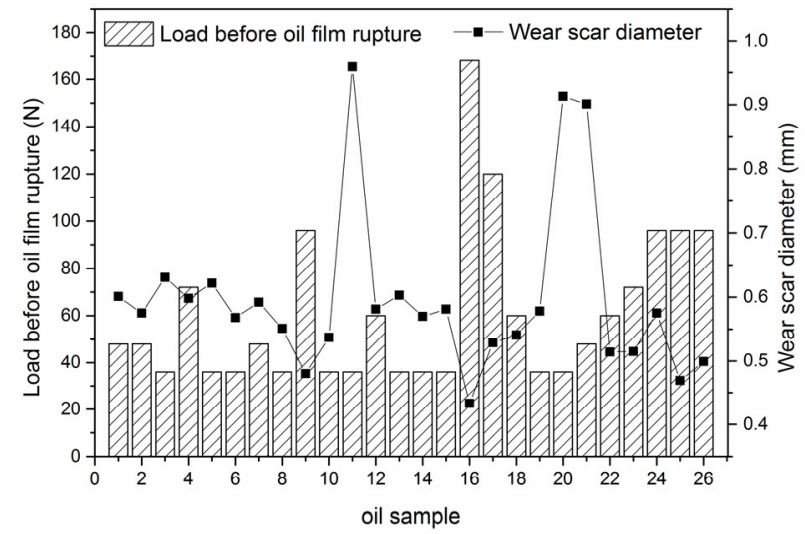

Fig. 5. Tribological properties of 26 kinds of domestic and foreign hydraulic oils.

The test results are shown in figure 5. The scratch resistance of common commercial high-pressure hydraulic oil was concentrated at level of $36 \mathrm{~N}$; the antiscratch ability of hydraulic transmission dual-use oil was $96 \mathrm{~N}$ or higher, and can be as high as $168 \mathrm{~N}$. The bearing capacity of high-pressure hydraulic oil and hydraulic transmission dual-use oils is obviously different.

The wear scar diameters of high pressure hydraulic oils fluctuated from $0.54 \mathrm{~mm}$ to $0.63 \mathrm{~mm}$, while that of hydraulic transmission dual-purpose oils mainly fluctuates between $0.43 \mathrm{~mm}$ and $0.53 \mathrm{~mm}$, which indicates that the anti-wear performance of different formulations of hydraulic oil is obviously different.

It is well known that lubricating additives have a decisive influence on the tribological properties of oils, additives cause differences in tribological properties. The point contact four-ball test and the line contact ring block test can evaluate the anti-wear and extreme pressure performance of hydraulic oil from multiple angles.

Data statistical analysis on the extreme pressure and anti-wear performance of 26 kinds of oils, the correlation coefficient is $-0.485, \mathrm{P}$ value is 0.012 . To a certain extent, extreme pressure and anti-wear performance are negatively related. Hydraulic oil with good extreme pressure performance may have good anti-wear performance. The two methods represent two contact modes, which increase the reliability of oil tribological performance evaluation.

\section{Conclusions}

Based on the experimental and analytical investigations presented in this paper, the following conclusions have been drawn:

(1) Under rotation speed of $600 \mathrm{r} / \mathrm{min}$, temperature of $96{ }^{\circ} \mathrm{C}$, during time of $90 \mathrm{~min}$, the best condtion for testing the anti-wear performance with a four-ball machine is load of $588 \mathrm{~N}$, for the block-on-ring tester is the load before the oil film ruptures.

(2) The test conditions and methods under point and line motion modes can distinguish anti-wear and extreme pressureperformance of hydraulic oils, these methods can provide a basis for selection of lubricating oil in hydraulic system.

(3) Through the correlation analysis of anti-wear and extreme pressure performance, it is found that there was a negatively correlation between extreme pressure and antiwear performance.

\section{References}

1. X.Z.Tang, M.R.Su, F.C.Huang, etal.Development and application of special anti-wear hydraulic oil used in engineering machinery $[\mathrm{J}]$. Contemporary Chemical Industry, 2013,42(6):725-729.

2. Z.J.Guan, G.F.Zhong, H.Y.Zhang, etal. The selection of construction machinery hydraulic system hydraulic oil $[\mathrm{J}]$. Petroleum Products Application Research, 2007, 25 (6):30-32.

3. J.J.Tang. Upgrade of anti-wear hydraulic oil specification $[\mathrm{J}]$. Petroleum Products Application Research, 2006 (06): 70-77.

4. Z.G.Liu, Y.B.Zheng, Y.M.Liu, etal. Study on wear resistance of hydraulic Oil [J]. Hydraulics Pneumatics \& Seals, 2018(12): 30-33.

5. B.T.Liu, H.Gao, H.Zhou, etal. Applications of fourball testers in evaluation of liquid lubricants [J]. Physical Testing and Chemical Analysis (Part A: Physical Testing), 2015(11):795-798.

6. B.T.Liu, H.Gao, J.J.Zhang, etal. Research progress on evaluation methods of tribological properties of lubricants [J]. Physical Testing and Chemical Analysis (Part A: Physical Testing), 2019, 55(2):97101. 